\title{
Application of ANN and fuzzy logic algorithms for streamflow modelling of Savitri catchment
}

\author{
Mahesh Kothari ${ }^{1}$ and K D Gharde ${ }^{2, *}$ \\ ${ }^{1}$ Department of Soil and Water Engineering, College of Technology and Engineering, Maharana Pratap \\ University of Agriculture 83 Technology, Udaipur 313 001, India. \\ ${ }^{2} S W C E$, College of Technology and Engineering, Maharana Pratap University of Agriculture 85 Technology, \\ Udaipur, India. \\ ${ }^{*}$ Corresponding author. e-mail: aryanavipsha2010@gmail.com
}

The streamflow prediction is an essentially important aspect of any watershed modelling. The black box models (soft computing techniques) have proven to be an efficient alternative to physical (traditional) methods for simulating streamflow and sediment yield of the catchments. The present study focusses on development of models using ANN and fuzzy logic (FL) algorithm for predicting the streamflow for catchment of Savitri River Basin. The input vector to these models were daily rainfall, mean daily evaporation, mean daily temperature and lag streamflow used. In the present study, 20 years (1992-2011) rainfall and other hydrological data were considered, of which 13 years (1992-2004) was for training and rest 7 years (2005-2011) for validation of the models. The mode performance was evaluated by R, RMSE, $\mathrm{EV}, \mathrm{CE}$, and MAD statistical parameters. It was found that, ANN model performance improved with increasing input vectors. The results with fuzzy logic models predict the streamflow with single input as rainfall better in comparison to multiple input vectors. While comparing both ANN and FL algorithms for prediction of streamflow, ANN model performance is quite superior.

\section{Introduction}

New algorithms and models, especially those based on soft computing, enable researchers to solve the most complex systems in different ways. The use of forecast methods not based on physics equations, such as artificial neural network (ANN) and fuzzy logic (FL) methods are becoming widespread in various engineering fields. The relationship between rainfall and streamflow is an important issue in surface hydrology. The accurate amount of streamflow from rainfall occupies an important place in the hydrological cycle. The amount of streamflow from rainfall is necessary to predict for avoiding risk and assessment of flood.
The ANN is widely adopted for modelling of hydrologic process, including rainfall streamflow process (Hsu et al.1995). Fernando and Jayawardena (1998) studied on streamflow forecasting using radial basis function (RBF) networks with orthogonal least square (OLS) algorithm. Tokar and Johnson (1999) developed ANN model to predict daily streamflow from daily rainfall, evaporation, temperature and snowmelt for watershed. ANN can also be applied to streamflow forecasting (Shivakumar et al. 2002; Sinha Jitendra et al. 2013), reservoir inflow forecasting (Jain and Srivastava 1999), sediment yield modelling (Raghuwanshi et al. 2006; Senthil Kumar et al. 2012). In many previous studies, ANN type such as multi-layer feed-foreword back-propagation

Keywords. Transferred function; Sigmoid; back-propagation; membership function; defuzzification. 
neural network (MLFBPN) was commonly adopted and it proved to be the most powerful tool to $80 \%$ of practical application in all fileds of hydrologic engineering and sciences (Hsu et al. 1995; Smith and Sli 1995). In the present study, we have developed multi-layered feed-forward back-propagation neural network model with rainfall, temperature, evaporation, and lag streamflow as input to predict streamflow. Senthil Kumar et al. (2012) and Raghuwanshi et al. (2006) have applied the ANN model for prediction of suspend yield on weekly and monthly basis for eastern coast river but in the present study, streamflow was predicted by ANN and fuzzy logic models on a daily basis for the western coastal belt of Maharashtra which falls in a different agroecological zone.

Zadeh (1965) developed the fuzzy set theory with relative membership concept and proposed the fuzzy optimum theory (Tayfur et al. 2003), which has a better practical application in engineering field. Based on the fuzzy optimum theory, a new fuzzy neural network for streamflow forecast is introduced. Yeshewatesfa et al. (2001) applied FL model for rainfall streamflow modelling. The past decade has witnessed applications of fuzzy logic approach in water resources (Nayak et al. 2005). Nayak et al. (2005) used Mamdani approach (Mamdani and Assilian 1975), which has been used in some hydrological applications for rainfall streamflow modelling. Gowda and Moyya(2014) apply fuzzy logic model for predicting streamflow for Nethravathi River Basin which is located in Dakshina Kannada, applying different membership functions and results. They found that, fuzzy inference system using triangular membership function show a good performance compared to other models developed. The fuzzy logic approach has also beenapplied to flood forecasting (Chang et al. 2005), precipitation (Maskey et al. 2004), sediment transport(Tayfur et al. 2003), reservoir operation (Tilmant et al. 2002), and storm water infiltration (Hong et al. 2002). This study develops an FL model to simulate event-based streamflow. The model employs mean daily rainfall, temperature and evaporation in the input vector of the algorithm. Tayfur and Singh (2006) used ANN and fuzzy logic models for simulating event-based rainfall-streamflow. Mukerji et al. (2009) apply the ANN, ANFIS and ANFGI mode to forecast streamflow for Ajay River Basin in Jharkhand, India and the results observed that ANFIS model predicts better than the ANN model in most of the cases. The aim of present study was to develop the ANN and FL models for predicting the streamflow with different input vectors and evaluate the comparative performance of both models. The present study deals with the prediction of streamflow by ANN and FL models on daily time step suitable for short term forecasting of streamflow for catchments having heavy flood during monsoon period and with an undulating heavy slope.

\section{Materials and methods}

\subsection{Study area and data used}

The present study was conducted for the Savitri River Basin that comes under the western part of Sahyadri Ghat of Konkan region, located in the state of Maharshtra, India (figure 1). The latitude and longitude of the study area is $18^{\circ} 20^{\prime}-17^{\circ} 51^{\prime} \mathrm{N}$ and $73^{\circ} 22^{\prime}-73^{\circ} 41^{\prime} \mathrm{E}$ respectively and elevation ranges from 6.50 to $1366.23 \mathrm{~m}$ above mean sea level (msl). The mean aerial average of rainfall, evaporation and temperature were taken for modelled daily streamflow for a duration of 20 years (19922011) of all stations covered in the catchments. The statistical parameters of input data for models such as mean, maximum, minimum, standard deviation (SDV), autocorrelation function (ACF) and partial autocorrelation function (PACF) coefficient were estimated using standard procedure (table 1).

\subsection{Input to models}

A multi-layer feed-forward network with 1-7 input layers; one hidden layer with different combination of neuron and one output layer ANN was developed. Mamdani type fuzzy logic triangular MF algorithm was adopted. Different combination of input layers were adjusted and checked the performance of models. The combinations of input parameters are presented in table 2 for identification of best model for ANN and for FL (table 5). Eleven ANN models were developed for Savitri basin to forecast streamflow on the basis of different inputs whereas it was four for FL. The data from 13 years (1992-2004) comprising of 1600 sets were used in training the model whereas data of 7 years (2005-2011) comprising of 883 sets were used for cross validation of models.

\subsection{Artificial neural network}

An ANN is a highly interconnected network of many simple processing units called neurons, which are analogous to the biological neurons in the human brain. Neurons having similar characteristics in an ANN are arranged in groups called layers. The neurons in one layer are connected to those in the adjacent layers, but not to those in the same layer. The strength of connection between the two neurons in adjacent layers is represented by what is known as a 'connection strength' or 'weight'. An ANN normally consists of three layers: an input 


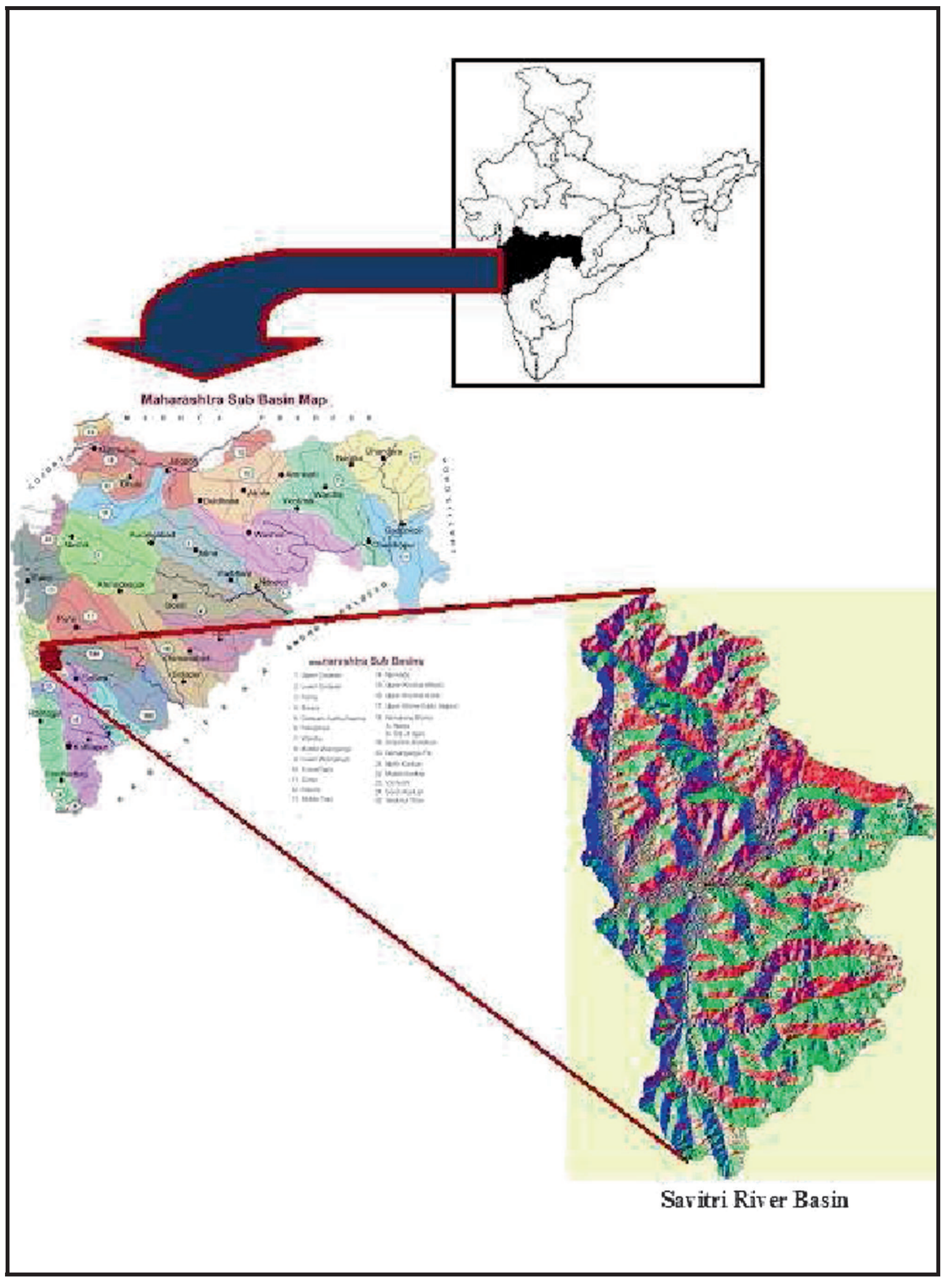

Figure 1. Location of Savitri Basin. 
Table 1. Statistical properties of input data used in ANN and fuzzy logic modelling for Savaitri Basin.

\begin{tabular}{|c|c|c|c|c|c|c|c|c|c|}
\hline Sl. no. & Data & Dataset & Max & Min & Mean & $\mathrm{SD}$ & $\mathrm{ACF}$ & $\mathrm{PACF}$ & $\mathrm{SE}$ \\
\hline 1 & Rainfall, mm & 2483 & 366.9 & 0.1 & 28.14 & 36.56 & 0.009 & 0.014 & 0.02 \\
\hline 2 & Runoff, cumecs & 2383 & 4932.3 & 0.01 & 395.12 & 532.31 & 0.014 & 0.004 & 0.02 \\
\hline 3 & Temperature, ${ }^{\circ} \mathrm{C}$ & 2383 & 40.3 & 23.9 & 29.78 & 2.44 & 0.171 & 0.016 & 0.02 \\
\hline 4 & Evaporation, E, mm & 2383 & 16.0 & 0.2 & 3.36 & 1.25 & 0.106 & 0.016 & 0.02 \\
\hline
\end{tabular}

Table 2. Input parameters and ANN structure of different model for Savitri Basin.

\begin{tabular}{|c|c|c|c|c|}
\hline Model no. & $\begin{array}{l}\text { Models input } \\
\text { parameters }\end{array}$ & $\begin{array}{c}\text { No. of } \\
\text { input parameters }\end{array}$ & $\begin{array}{l}\text { No of neurons in } \\
\text { the hidden layer }\end{array}$ & $\begin{array}{c}\text { Model } \\
\text { structure }\end{array}$ \\
\hline M1 & $\mathrm{Q}_{\mathrm{t}}=\mathrm{P}_{\mathrm{t}}$ & 1 & 20 & 11201 \\
\hline M2 & $\mathrm{Q}_{\mathrm{t}}=\mathrm{P}_{\mathrm{t}}, \mathrm{P}_{\mathrm{t}-1}$ & 2 & 12 & 21121 \\
\hline M3 & $\mathrm{Q}_{\mathrm{t}}=\mathrm{P}_{\mathrm{t}}, \mathrm{P}_{\mathrm{t}-1}, \mathrm{P}_{\mathrm{t}-2}$ & 3 & 10 & 31101 \\
\hline M4 & $\mathrm{Q}_{\mathrm{t}}=\mathrm{P}_{\mathrm{t}}, \mathrm{P}_{\mathrm{t}-1}, \mathrm{P}_{\mathrm{t}-2}, \mathrm{E}_{\mathrm{t}}$ & 4 & 15 & 41151 \\
\hline M5 & $\mathrm{Qt}=\mathrm{P}_{\mathrm{t}}, \mathrm{P}_{\mathrm{t}-1}, \mathrm{P}_{\mathrm{t}-2}, \mathrm{~T}_{\mathrm{t}}$ & 4 & 10 & 41101 \\
\hline M6 & $\mathrm{Q}_{\mathrm{t}}=\mathrm{P}_{\mathrm{t}}, \mathrm{P}_{\mathrm{t}-1}, \mathrm{P}_{\mathrm{t}-2}, \mathrm{E}_{\mathrm{t}}, \mathrm{T}_{\mathrm{t}}$ & 5 & 15 & 51151 \\
\hline M7 & $\mathrm{Q}_{\mathrm{t}}=\mathrm{P}_{\mathrm{t}}, \mathrm{P}_{\mathrm{t}-1}, \mathrm{P}_{\mathrm{t}-2}, \mathrm{Q}_{\mathrm{t}-1}$ & 4 & 15 & 41151 \\
\hline M8 & $\mathrm{Q}_{\mathrm{t}}=\mathrm{P}_{\mathrm{t}}, \mathrm{P}_{\mathrm{t}-1}, \mathrm{P}_{\mathrm{t}-2}, \mathrm{Q}_{\mathrm{t}-1}, \mathrm{Q}_{\mathrm{t}-2}$ & 5 & 14 & 51141 \\
\hline M9 & $\mathrm{Q}_{\mathrm{t}}=\mathrm{P}_{\mathrm{t}}, \mathrm{P}_{\mathrm{t}-1}, \mathrm{P}_{\mathrm{t}-2}, \mathrm{Q}_{\mathrm{t}-1}, \mathrm{Q}_{\mathrm{t}-2}, \mathrm{E}_{\mathrm{t}}$ & 6 & 14 & 61141 \\
\hline M10 & $\mathrm{Q}_{\mathrm{t}}=\mathrm{P}_{\mathrm{t}}, \mathrm{P}_{\mathrm{t}-1}, \mathrm{P}_{\mathrm{t}-2}, \mathrm{Q}_{\mathrm{t}-1}, \mathrm{Qt}_{-2}, \mathrm{~T}_{\mathrm{t}}$ & 6 & 9 & 6191 \\
\hline M11 & $\mathrm{Q}_{\mathrm{t}}=\mathrm{P}_{\mathrm{t}}, \mathrm{P}_{\mathrm{t}-1}, \mathrm{P}_{\mathrm{t}-2}, \mathrm{Q}_{\mathrm{t}-1}, \mathrm{Q}_{\mathrm{t}-2}, \mathrm{E}_{\mathrm{t}}, \mathrm{T}_{\mathrm{t}}$ & 7 & 10 & 71101 \\
\hline
\end{tabular}

layer, a hidden layer and an output layer. In a feedforward network, the weighted connections feed activations only in the forward direction from an input layer to the output layer.

In the present study, the back-propagation algorithm (Rumelhart et al. 1986) is used in multilayered feed-forward ANNs. The back-propagation algorithm uses supervised learning that provides the algorithm with examples of the inputs and outputs and then the error (difference between actual and expected results) is calculated. The activation function of the artificial neurons in ANNs, implementing the back-propagation algorithm is a weighted sum (the sum of the inputs $P_{t-1}$ multiplied by their $j-i$ respective weights $w$ ). Architecture of artificial neural network adopted is shown in figure 2. The expression written in the mathematical form for ANN model given by equation (1) as follows:

$$
\begin{gathered}
Q(t)=f\left(S R, P\left(t_{l}\right), P\left(t_{l-1}\right), P\left(t_{l-2}\right), Q\left(t_{s-1}\right),\right. \\
\left.Q\left(t_{s-2}\right), T t, E t\right)
\end{gathered}
$$

where $t$ is the time of prediction, days $(24 \mathrm{hr})$; $t_{1}$ is the time to incorporate rainfall (in this case, $\left.t_{l}=t_{l-2}\right) ; t_{-1}$ is the time period $(24 \mathrm{hr}), P$ is the daily rainfall $(\mathrm{mm}) ; P_{t-1}$ is the daily rainfall lag by one day, $\mathrm{mm}(24 \mathrm{hr}) ; P_{t-2}$ is the daily rainfall lag by two day, $\mathrm{mm}(48 \mathrm{hr}) ; Q_{t}$ is the daily stream flow, (cumecs); $Q_{t-1}$ is the stream flow lag by one day, cumecs $(24 \mathrm{hr}) ; Q_{t-2}$ is the stream flow lag by two day, cumecs $(48 \mathrm{hr}) ; T_{t}$ is the daily mean temperature, ${ }^{\circ} \mathrm{C} ; E_{t}$ is the daily mean evaporation, $\mathrm{mm}$;

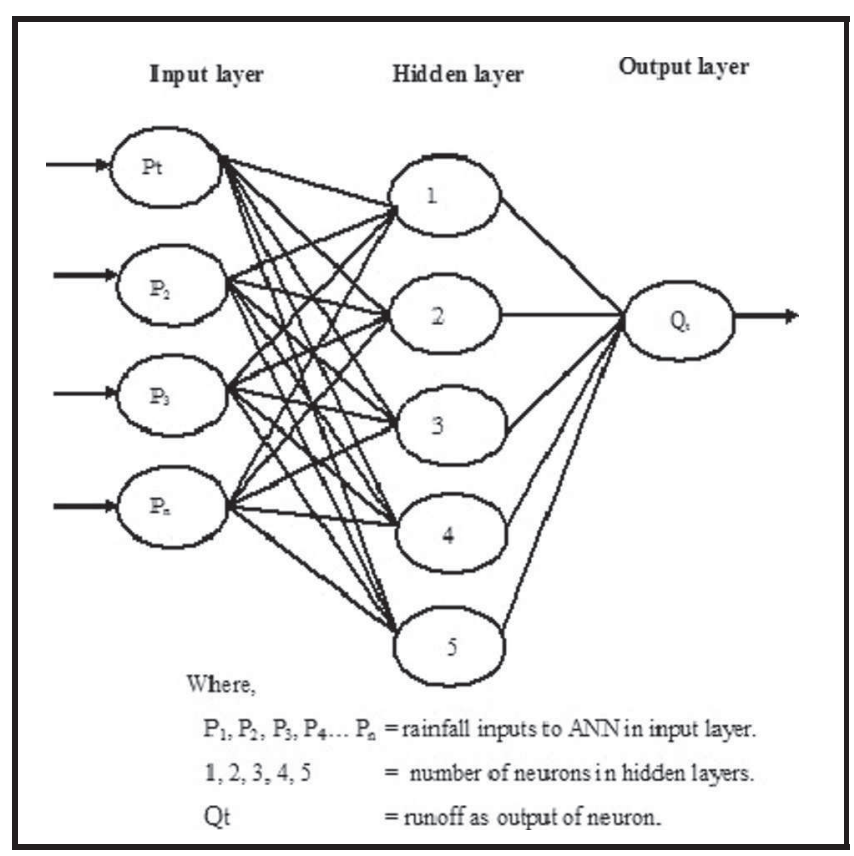

Figure 2. Architecture of feed-forward multi-layer perception (MLP) ANN model.

and $S R$ is the summation of rainfall value from $t_{l}$ to $t_{l-2}(\mathrm{~mm})$.

\subsubsection{Transfer function}

The transfer function of a neuron in a neural network is only a processing function. It is utilized for limiting the amplitude of the output of a neuron. It gives output in a range of 0 to 1 . The sigmoid transfer function $f(\alpha)$ is commonly used in the 


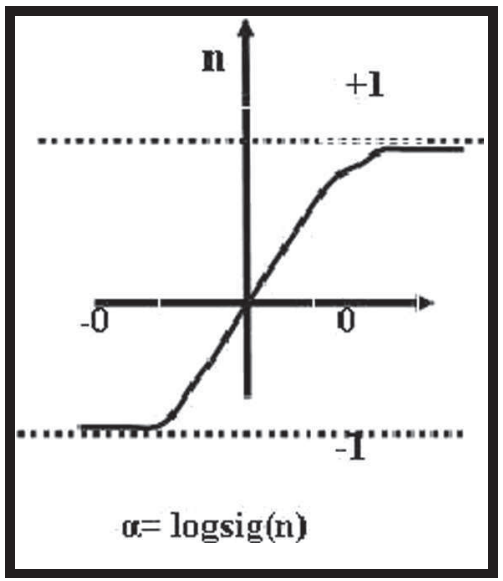

Figure 3. Sigmoidal transferred function. hidden layers of multilayer ANN networks as given in figure 3 and it is represented by equation (2)

$$
f(\alpha)=\frac{1}{1+e^{-\alpha}} .
$$

\subsubsection{Pre-processing of data}

A logistic sigmoid is used here as the transfer function and the observed input parameters (rainfall, streamflow, temperature and evaporation) are normalized using equation (3). The transformation bounded in the range of $0.1-0.99$.

$$
X_{n}=0.1+0.8 X\left(\frac{X_{\text {value }}-X_{\min }}{X_{\max }-X_{\min }}\right)
$$

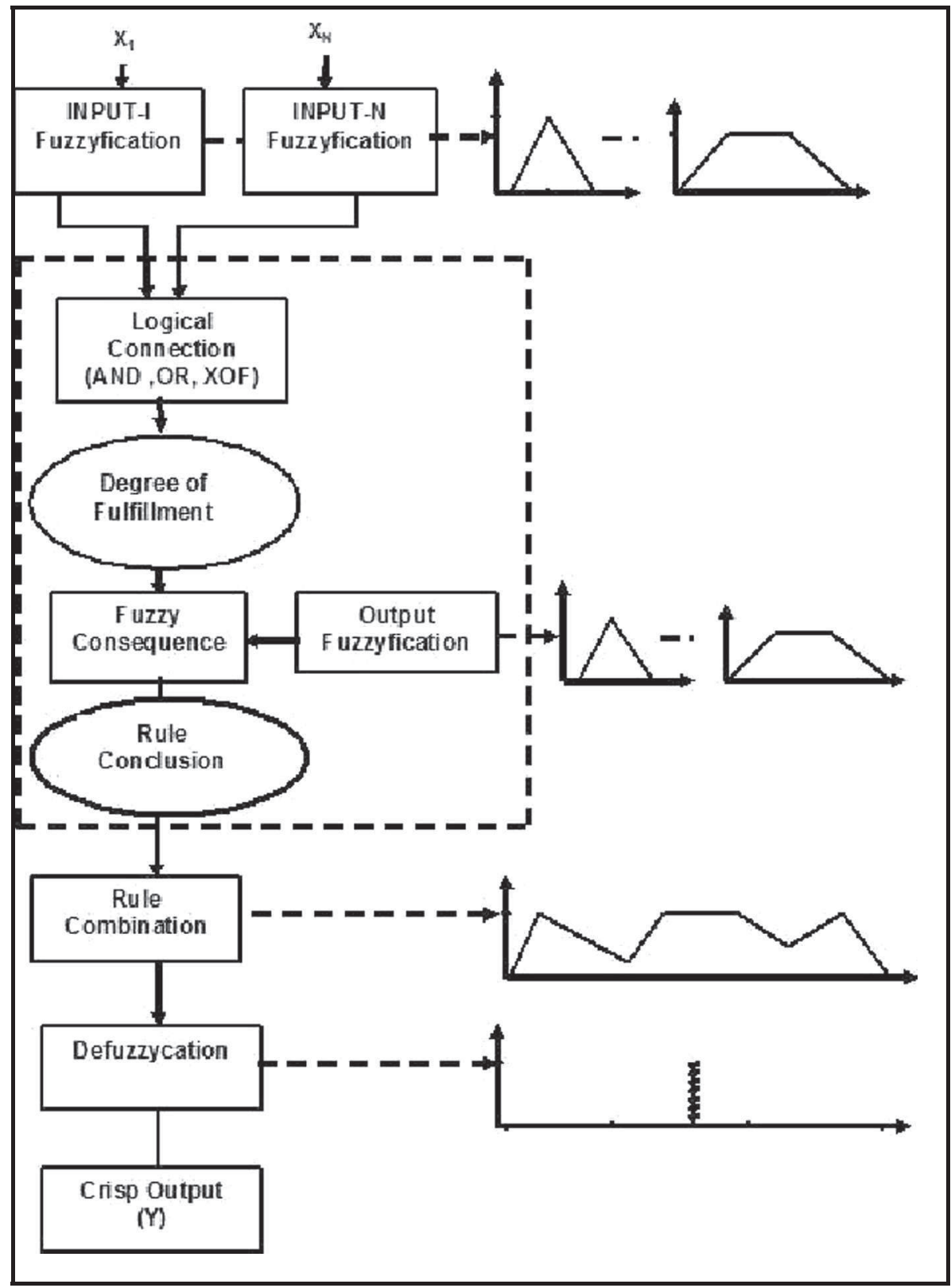

Figure 4. Schematic operation of FL model. 
where $X_{n}$ is the normalized dataset; $X_{\text {value }}$ is the original dataset; $X_{\min }$ is the minimum value of dataset and $X_{\max }$ is the maximum value of dataset.

\subsubsection{ANN training}

ANN models are trained based on supervised training procedure which allows the network to simulate the hydrological system by examining inputoutput examples from it. Work by Samani et al. (2007) show that the popular steepest-descent back-propagation algorithm is easily performed by second-order gradient algorithms and a wider consensus has been reached that such algorithms are therefore preferable over first-order methods.

\subsection{Fuzzy logic (FL)}

The fuzzy logic referred to a logical system that generalizes classical two valued logic for reasoning under uncertainty. A general fuzzy system has basically four components as fuzzification, fuzzy rule base, fuzzy output engine, and defuzzification (figure 4).

\subsubsection{Fuzzy sets}

Fuzzy set assigns the value referred to as the membership function associated with the fuzzy members. Fuzzy numbers are special types of fuzzy sets defined on the set of real numbers. Fuzzy numbers are usually defined by using membership functions that have triangular shapes. Other functions, such as the Gaussian function and trapezoidal, can also be used as membership functions, but these increase the computational effort and provide no noticeable performance improvement (figure 5).

\subsubsection{Fuzzy logic control}

Fuzzy logic control is to influence the behaviour of a system by changing an input or inputs to that system according to a rule or set of rules that model how the system operates. The system being controlled may be meteorological parameter such as rainfall to streamflow. A fuzzy controller is a controller that uses a collection of fuzzy membership functions and rules to reason about data.

\subsubsection{Membership functions}

Membership functions in the universe of discourse is a member of a fuzzy set to some grade (may be even zero). The set of elements that have a non-zero membership is called the support of the fuzzy set. The function that ties a number to each element of the universe is called the membership function.

\subsubsection{Fuzzification}

Fuzzification is the process which converts each piece of input data to degree of membership by the lookup in one or several membership functions. It is the degree of membership for each linguistic term that applies to that input variable. In the present study, input $\left(P_{t}\right)$, temperature $\left(T_{t}\right)$ and evaporation $\left(E_{t}\right)$ and output $\left(Q_{t}\right)$ were fuzzified into fuzzy subsets by using triangular membership functions in order to cover the whole range of changes. The criterion of defining fuzzy subsets is based on subjective perception of specific linguistic level by relevant experts. All input and output variables were separately divided into subsets, as extremely low (EL), very low (VL), low (L), medium low (ML), medium $(\mathrm{M})$, medium high $(\mathrm{MH})$, high $(\mathrm{H})$, very high (VH) and extremely high (EH). Total of 9 subsets were selected for inputs and same were selected for output variables. More subsets are considered to increase the accuracy of prediction.

\subsubsection{Fuzzy interference system and formation of rules}

Fuzzy interference system and formation of rules is inference to an engine that takes into account all

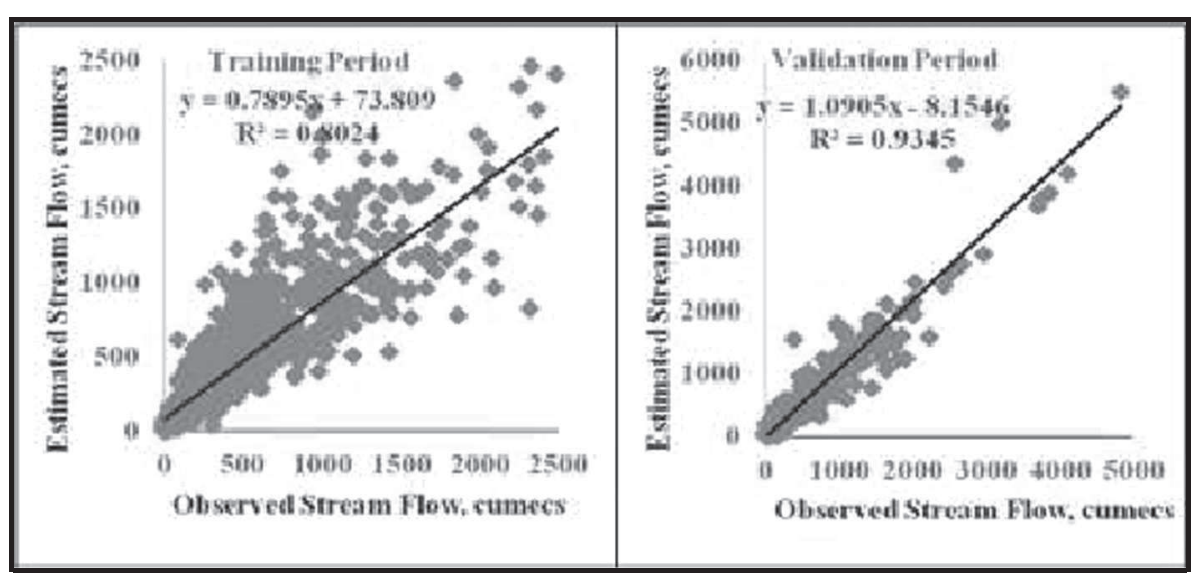

Figure 5. Scatter plot of observed and estimated runoff for M11. 
the fuzzy rules to learn how to transform a set of inputs to corresponding outputs. The activation of a rule is the deduction of the conclusion, possibly reduced by its firing strength. The following fuzzy rules are constructed as samples:

$$
\begin{aligned}
& \text { IF } P_{t} \text { is low and } \mathrm{P}_{t-1} \text { is low } \\
& \text { THEN } Q_{t} \text { is very low; } \\
& \text { IF } P_{t} \text { is high } \\
& \text { THEN } Q_{t} \text { is high. }
\end{aligned}
$$

The next subprocess in inference is the composition subprocess where all of the fuzzy subsets assigned to the output variable are combined together to form a single subset for the output variable. There are basically two composition methods, maximization (max)and summation (sum). In max composition, the combined output fuzzy subset is constructed by taking the pointwise maximum over all of the fuzzy subsets assigned to the output variable by the inference rule. In sum composition, the combined output fuzzy subset is constructed by taking the pointwise sum over all of the fuzzy subsets. Consequently, in sum composition it is sometimes possible to obtain truth values greater than one.

\subsubsection{Defuzzifications}

Defuzzifications is the process which converts the fuzzy value into a 'crisp' value. There are many defuzzification methods, such as centre of gravity (COG), bisector of area (BOA), mean of maxima (MOM), left-most maximum (LM), and right-most maximum (RM) etc (Sen 1999). The BOA method picks the abscissa of the vertical line that divides the area of the combined output fuzzy subset in two equal halves. In the COG method, the crisp output value is the abscissa under the centre of gravity of the combined output fuzzy subset. The COG method is the most commonly used defuzzification method. Hence, in the present study, the most common COG method of defuzzification was adopted and expressed by equation (6)

$$
C_{g}=\frac{\sum_{i=1}^{n} y_{i} X M_{B}\left(y_{i}\right)}{\sum_{i=1}^{n} M_{B}\left(y_{i}\right)}
$$

where $C_{g}$ is the the centroid of the truncated fuzzy output set $B ; M_{B}\left(y_{i}\right)$ is the membership value of element $y_{i}$ in the fuzzy output of set $B$ and $n$ is the number of elements.

\subsection{Performance evaluation model results}

A number of statistical criteria have been suggested by researchers (Nash and Sutcliffe 1970; Abraham and Ledoltor 1983) to evaluate the performance of rainfall streamflow models. To assess the accuracy of a rainfall-streamflow model, more than one criterion should be used. The model performances were evaluated using correlation coefficient $(R)$, root mean square error (RMSE), mean absolute deviations (MAD), coefficient of efficiency (CE), and volumetric error (EV) and these are expressed as the following mathematical equations:

\subsubsection{Correlation coefficient $(R)$}

$R=\frac{\sum_{i=1}^{N}\left\{\left(Q_{\mathrm{obs} i}-\overline{\left.Q_{\mathrm{obs} i}\right)}\left(Q_{\operatorname{sim} i}-\overline{\left.Q_{\operatorname{sim} i}\right)}\right\}\right.\right.}{\sqrt{\sum_{i=1}^{N}\left(Q_{\mathrm{obs} i}-\overline{\left.Q_{\mathrm{obs} i}\right)^{2}} \cdot \sum_{i=1}^{N}\left(Q_{\operatorname{sim} i}-\overline{Q_{\operatorname{sim} i}}\right)^{2}\right.}}$

where $Q_{\text {obs }}$ is the observed streamflow, cumecs; $Q_{\text {sim }}$ is the simulated streamflow, cumecs; and $N$ is the number of observations.

\subsubsection{Root mean square error (RMSE)}

$$
\operatorname{RMSE}=\left(\frac{\sum_{i=1}^{N}\left(Q_{\mathrm{obs} i}-Q_{\mathrm{sim} i}\right)^{2}}{N}\right)^{\frac{1}{2}} .
$$

2.5.3 Mean absolute deviation (MAD)

$$
\mathrm{MAD}=\frac{\sum_{i=1}^{N}\left|Q_{\mathrm{obs} i}-Q_{\operatorname{sim} i}\right|}{N} .
$$

\subsubsection{Coefficient of efficiency (CE)}

$$
\begin{aligned}
& \mathrm{CE}= 1-\left(\frac{\sum_{i=1}^{N}\left(Q_{\mathrm{obs} i}-Q_{\mathrm{sim} i}\right)^{2}}{\sum_{i=1}^{N}\left(Q_{\mathrm{obs} i}-\bar{Q}_{\mathrm{obs}}\right)^{2}}\right) \\
& 2.5 .5 \text { Volumetric error }(E V) \\
& \mathrm{EV}=\left\{\frac{\sum_{i=1}^{n}\left(Q_{\mathrm{sim} i}-Q_{\mathrm{obs} i}\right)}{\sum_{i=1}^{n} Q_{\mathrm{obs} i}}\right\} \times 100 .
\end{aligned}
$$

\section{Results and discussions}

The study was conducted to develop ANN and FL models for Savitri Basin to predict streamflow. In the development of ANN and FL models, three steps need to be followed are identification, validation of model and adoption of model on statistical performance in the development of hydrologic models. In the present study, 11 ANN and 4 FL models were developed with different inputs. Their performances were evaluated by statistical parameters $R, \mathrm{RMSE}, \mathrm{CE}, \mathrm{EV}$ and MAD.

\subsection{Performance evaluation of ANN model}

The streamflow was forecasted from different combination of inputs (rainfall, rainfall lag by one and 
two days, evaporation, temperature, streamflow lag by one and two days) in METLAB 2.9b for arterial neural network (ANN) model. The ANN model was developed with multi-layer feed-forward back propagation (MLFBP) using logistic sigmoid transferred function. The models were adopted on trial and error basis and performance of the models are shown in combination of number of neurons in hidden layers.

The ANN model performed better with more number of neurons in hidden layers as identified and is presented in table 2. The statistical performances of selected models with different inputs were evaluated for training period (1992-2004) and cross-validation period (2005-2011). It is observed from table 2 that the M1 with one input as daily rainfall, one output as streamflow and one hidden layer with 20 neurons was found with $R$ values of 0.68 in training period and 0.728 in cross-validation period and it was lowest among all the 11 models developed. The performance of ANN model with single inputs on the basis of other statistical indicators such as RMSE, CE, EV, and MAD for training and cross-validation period were observed 390.09 cumecs, $46.89 \%, 3.37 \%, 13.41 \%$, and 361.16 cumecs, $55.00 \%, 1.55 \%, 3.34 \%$, respectively. It is also observed that increasing the number of inputs increases the $R$ values subsequently in training and cross-validation. The highest value of $R$ was observed for M11 under training period, but M7, M8, M9, M10 and M11 gave the highest value of $R$ (more than 0.96) in case of validation. It indicates that the ANN performed better in cross-validation period over the training period. The RMSE is found more with less input and reduces with addition of lag streamflow by one or two days. The RMSE for the first six models ranges from 390.09 to 353.51 cumecs in training period whereas in crossvalidation period, it is $361.16-279.62$ cumecs. Its values decrease for M7, 8, 9, 10 and 11 as 270.80,
262.61, 270.98, 278.21 and 238.31 cumecs under training period whereas under cross-validation period, the values were $661.58,726.31,113.08,115.84$ and 161.65 cumecs, respectively. Hence, lowest value of RMSE was observed for M11 under training and M9 under cross-validation period. Sinha Jitendra et al. (2013) reported that the ANN model with single input as daily rainfall performed better in cross validation over training period. This may be due to the consistencies and variance in input datasets.

The model with minimum RMSE and $R$ approaches to 1 is considered to predict accurately in comparison with other models. In the same manner, when CE, EV approaches to 100, the model performance is best predicted. Except RMSE, M7 and M8 show high CE, minimum EV, and MAD over all other models under consideration. Hence, the model with input as rainfall and streamflow lags by one and two day improves the performance of the models in ANN modelling. The scatter plot of estimated streamflow and observed streamflow were developed for training period and cross-validation period for M11 ( $\left.\begin{array}{llll}7 & 1 & 10 & 1\end{array}\right)$ and is presented in figure 5 . The comparative plot of observed and estimated streamflow for M11 ( $\left.\begin{array}{llll}7 & 1 & 10 & 1\end{array}\right)$ is presented in figure 6 . From the above figure, it is observed that the M11 performed better for estimation of streamflow with ANN model developed (table 3).

\subsection{Fuzzy logic models performance evaluation}

The four models were developed and calibrated by using Mamdani FIS system with center of gravity (COG) method of defuzzification (table 4). The output of models was analyzed by performing statistical parameter for development stage and calibration period as presented in table 5. The inputs were combined with daily rainfall, temperature and evaporation and daily streamflow as output.

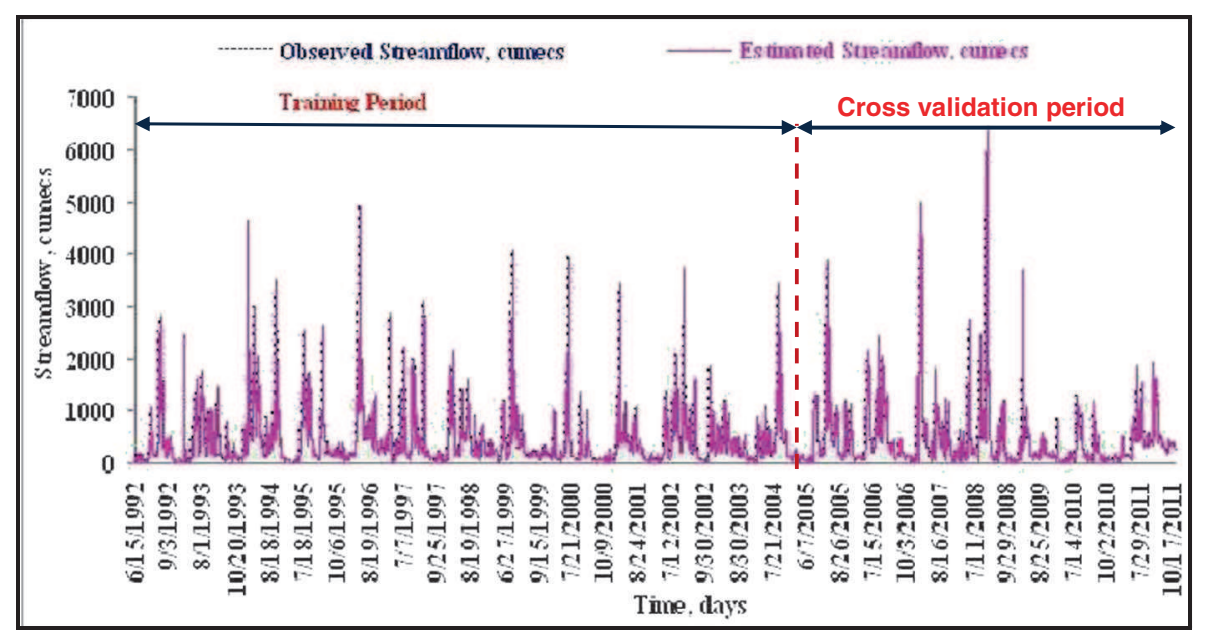

Figure 6. Comparison of observed and estimated runoff of ANN M11. 
Table 3. Statistical performance of different Ann models of Savitri Bain with different input parameter.

\begin{tabular}{|c|c|c|c|c|c|c|c|c|c|c|}
\hline \multirow[b]{2}{*}{ Model no. } & \multicolumn{5}{|c|}{ Training period (1992-2004) } & \multicolumn{5}{|c|}{ Cross-validation period (2005-2011) } \\
\hline & $\mathrm{R}$ & RMSE & $\mathrm{CE}$ & $\mathrm{EV}$ & MAD & $\mathrm{R}$ & RMSE & $\mathrm{CE}$ & $\mathrm{VE}$ & MAD \\
\hline M1 & 0.68 & 390.09 & 46.8 & 3.37 & 13.41 & 0.73 & 361.16 & 55.0 & 1.55 & 3.34 \\
\hline M2 & 0.75 & 358.96 & 55.0 & 17.6 & 70.42 & 0.85 & 279.62 & 71.8 & 7.34 & 15.79 \\
\hline M3 & 0.72 & 368.47 & 52.6 & 2.50 & 9.97 & 0.75 & 351.77 & 55.4 & 0.35 & 13.66 \\
\hline M4 & 0.77 & 353.51 & 56.3 & 20.7 & 82.70 & 0.85 & 285.27 & 70.6 & 11.70 & 25.17 \\
\hline M5 & 0.71 & 380.48 & 49.4 & 11.4 & 45.66 & 0.85 & 280.71 & 71.6 & 09.89 & 21.27 \\
\hline M6 & 0.75 & 356.03 & 55.7 & 4.70 & 18.72 & 0.84 & 287.60 & 70.1 & 10.70 & 23.02 \\
\hline M7 & 0.86 & 270.80 & 74.4 & 2.16 & 8.59 & 0.99 & 661.58 & 99.6 & 11.21 & 24.11 \\
\hline M8 & 0.87 & 262.61 & 76.0 & 0.19 & 0.74 & 0.99 & 726.31 & 99.6 & 12.26 & 26.36 \\
\hline M9 & 0.86 & 270.98 & 74.3 & 1.74 & 6.94 & 0.97 & 113.08 & 95.3 & 5.39 & 11.58 \\
\hline M10 & 0.85 & 278.21 & 72.9 & 0.25 & 0.98 & 0.97 & 115.84 & 95.1 & 8.21 & 17.65 \\
\hline M11 & 0.895 & 238.31 & 80.1 & 2.51 & 9.99 & 0.96 & 161.65 & 90.5 & 6.95 & 14.96 \\
\hline
\end{tabular}

Table 4. Input parameters and fuzzy logic structure.

\begin{tabular}{llcccc}
\hline Model no. & Models input & $\begin{array}{c}\text { Input } \\
\text { parameters }\end{array}$ & No. of rules & Defuzzification method & $\begin{array}{c}\text { Membership } \\
\text { function }\end{array}$ \\
\hline FLM1 & $\mathrm{Q}_{\mathrm{t}}=\mathrm{P}_{\mathrm{t}}$ & 1 & 17 & Centre of Gravity (COG) & Triangular \\
FLM2 & $\mathrm{Q}_{\mathrm{t}}=\mathrm{P}_{\mathrm{t}}, \mathrm{P}_{\mathrm{t}-1}$ & 2 & 34 & & \\
FLM3 & $\mathrm{Q}_{\mathrm{t}}=\mathrm{P}_{\mathrm{t}}, \mathrm{E}_{\mathrm{t}}$ & 2 & 34 & & \\
FLM4 & $\mathrm{Q}_{\mathrm{t}}=\mathrm{P}_{\mathrm{t}}, \mathrm{T}_{\mathrm{t}}$ & 2 & 34 & & \\
\hline
\end{tabular}

Table 5. Statistical performance of different fuzzy logic models of Savitri Basin.

\begin{tabular}{|c|c|c|c|c|c|c|c|c|c|c|}
\hline \multirow[b]{2}{*}{ Model no. } & \multicolumn{5}{|c|}{ Training period (1992-2004) } & \multicolumn{5}{|c|}{ Validation period $(2005-2011)$} \\
\hline & $R$ & RMSE & $\mathrm{CE}$ & EV & MAD & $R$ & RMSE & $\mathrm{CE}$ & $\mathrm{VE}$ & MAD \\
\hline FLM1 & 0.91 & 216.28 & 82.89 & 1.054 & -3.99 & 0.91 & 225.80 & 81.62 & 6.39 & -24.93 \\
\hline FLM2 & 0.87 & 269.00 & 73.53 & 1.236 & -4.69 & 0.91 & 236.84 & 79.78 & 14.46 & -56.36 \\
\hline FLM3 & 0.89 & 266.90 & 73.94 & 13.01 & -49.34 & 0.91 & 306.23 & 66.20 & 19.99 & -77.69 \\
\hline FLM4 & 0.70 & 424.7 & 34.03 & 11.55 & 43.79 & 0.91 & 355.72 & 54.39 & 24.88 & -96.95 \\
\hline
\end{tabular}

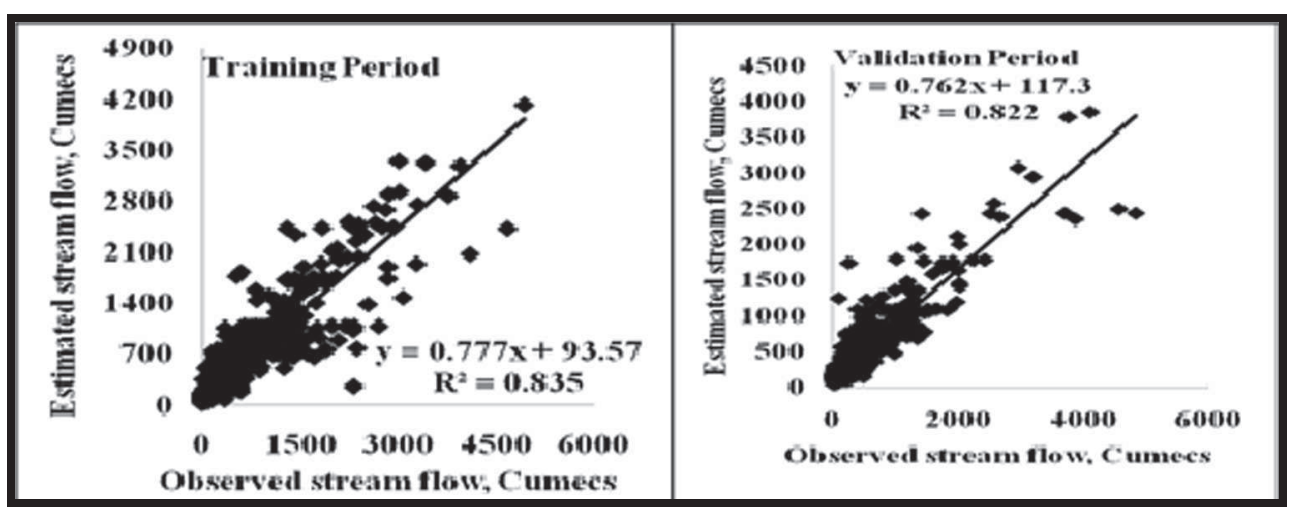

Figure 7. Scatter plot of observed and estimated streamflow by fuzzy logic during training and validation periods.

The sensitivity of output for FL models during developmental stage and calibration period was analyzed using $R$, RMSE, CE, VE and, MAD statistical parameters and is presented in table 5 . It is observed that $R$ value for developmental stage of models FLM1, FLM2, FLM3 and FLM4 were $0.916,0.867,0.884$ and 0.704 ; whereas during calibration period, it was $0.906,0.906,0.907$ and 


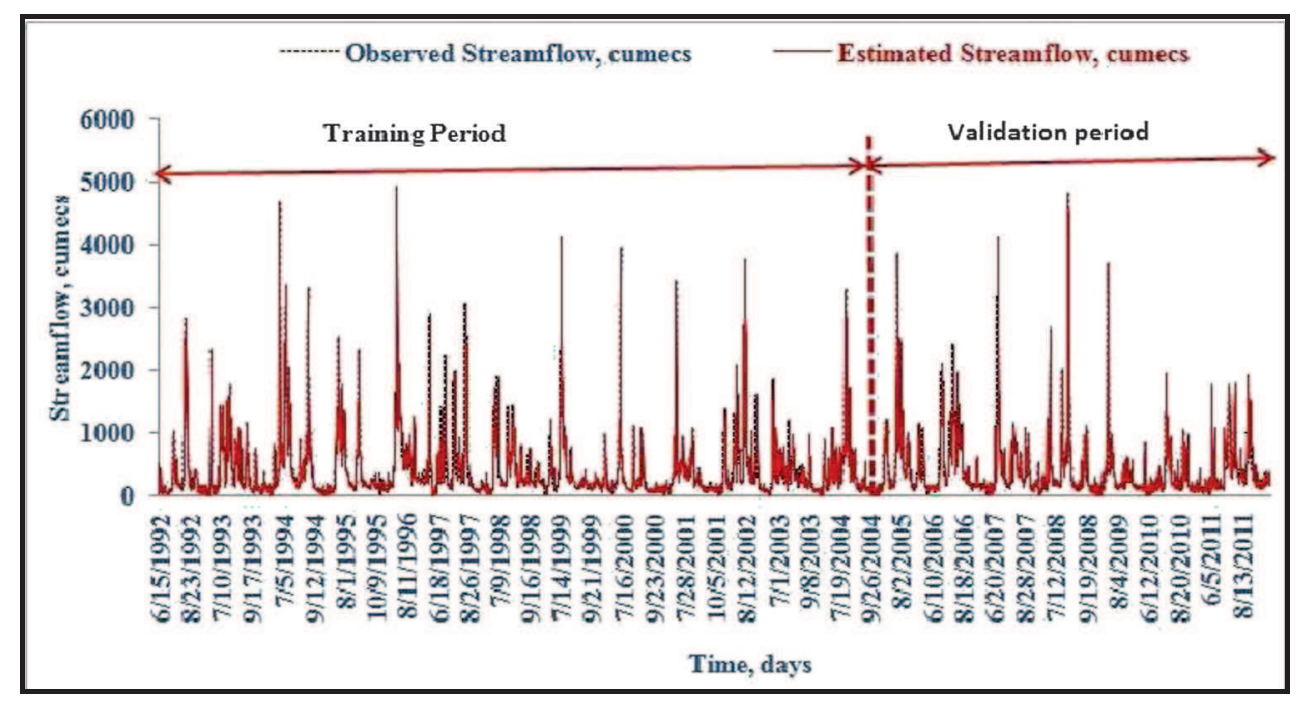

Figure 8. Comparison of observed and estimated streamflow by fuzzy logic during training and validation periods.

0.906, respectively. The value of $R$ approaching to 1 means the model performed better. It is observed from the above value that model performance in calibration period was much better compared to the developmental stage. The FLM1 performance during developmental stage is better compared to other models. It is also observed that RMSE of FLM1 is less during developmental (216.28 cumecs) and calibration period (225.8 cumecs) as compared to other models. Lesser value of RMSE indicates that the model performance is comparatively better to predict the streamflow. The other coefficient of efficiency (CE) of FLM1 is higher and approaching to 100 during developmental stage $(82.89 \%)$ and calibration period $(81.62 \%)$. This indicates that FLM1 performance is very good as compared to other model under study. The same trends were observed for volumetric efficiency (VE) and mean absolute deviation (MAD). The VE and MAD of FLM1 were observed to be less compared to other models. Hence, it is understood that model with single input as mean daily rainfall $(\mathrm{Pt})$ performed better as compared to other models with different inputs for predicting the streamflow in fuzzy logic modelling for Savitri Basin. The negative value of MAD indicated that the output of model was overestimated as compared to observed datasets. The comparative performance of developed models by applying physical checks and graphical scatter plot between observed and predicted streamflow for FL models is presented in figure 7 . The comparative performance of observed and estimated streamflow by FL model during developmental and calibration period is presented in figure 8 . FL model performed better in calibration period for all models and performance of FLM1 is better to other selected models.

\section{Conclusions}

The ANN and FL models were developed for Savitri Basin using different inputs such as rainfall, temperature, evaporation and lag streamflow in METLAB 2.9b. The performance of both models were evaluated by statistical indices such as $R$, MSRE, EV, CE and MAD. It is observed that ANN model performance increases significantly with increase in the number of inputs whereas FL model performs better with single input as rainfall. Comparatively, ANN model performance was found to be superior as compared to FL model in forecasting streamflow for Savitri Basin.

\section{Acknowledgements}

Authors are thankful to the Executive Engineer, Hydrologic Project Division, Nashik for providing streamflow and metrological data free of cost and to the Dean, College of Technology and Engineering, MPUAT, Udaipur for providing necessary facilities.

\section{References}

Abraham B and Ledoltor J 1983 Statistical methods for forecasting; John Wiley and Sons Inc., New York, 472p.

Chang L C, Chang F J and Sai Y H T 2005 Fuzzy exemplar-based inference system for flood forecasting; Water Resour. Res. 41, doi: 10.1029/2004WR003037.

Fernando D A K and Jayawardena A W 1998 Runoff forecasting using RBF networks with OLS algorithm; J. Hydrol. Eng. 3 203-209.

Jain S K and Srivastava D K 1999 Application of ANN for reservoir in flow prediction and operation; J. Water Resour. Plan. Manag. 125 263-271. 
Gowda C C and Moyya S D 2014 Runoff modelling using different membership functions in adaptive neuro fuzzy inference system; Int. J. Adv. Eng. Sci. 4(4) 48-51.

Hong Y S, Rosen M R and Reeves R R 2002 Dynamic fuzzy modelling of storm water infiltration in urban fractured aquifers; J. Hydrol. Eng. 7(5) 380-391.

Hsu K, Gupta H V and Sorooshian S 1995 Artificial neural network modelling of the rainfall-runoff process; Water Resour. Res. 31 2517-2530.

Mamdani E H and Assilian S 1975 An experiment in linguistic synthesis with a fuzzy logic controller; Int. J. Man-Machine Studies 7(1) 1-13.

Maskey S, Guinot V and Price R K 2004 Treatment of precipitation uncertainty in rainfall-runoff modelling: A fuzzy set approach; Adv. Water Resour. 27(9) 889-898.

Mukerji A, Chatterjee Chandranath and Raghuwanshi Narendra Singh 2009 Flood forecasting using ANN, Neuro-Fuzzy, and Neuro-GA models; J. Hydrol. Eng. 14(6) 647-652.

Nash J F and Sutcliffe J V 1970 River flow forecasting through conceptual models; J. Hydrol. Sci. 44 399-417.

Nayak P C, Sudheer K P and Ramasastri K S 2005 Fuzzy computing based rainfall-runoff model for real time flood forecasting; J. Hydrol. Process. 9 955-968.

Raghuwanshi N S, Singh R and Reddy L S 2006 Runoff and sediment yield modelling using artificial neural networks: Upper Siwane River, India; J. Hydrol. Eng. 11 71-79.

Rumelhart E, Hinton G and Williams R 1986 Learning internal representations by error propagation; Parallel Distributive Process 1 318-362.

Samani N, Gohari-Moghadam M and Safavi A A 2007 A simple neural network model for the determination of aquifer parameters; J. Hydrol. 340 1-11, doi: 0.1016/j.jhydrol.2007.03.017.

Senthil Kumar A R, Ojha C S P, Goyal Manish Kumar, Singh R D and Swamee P K 2012 Modelling of suspended sediment concentration at Kasol in India using ANN, fuzzy logic, and decision tree algorithms; J. Hydrol. Eng. ASAE 17(3) 394-404.

Sen Z 1999 Fuzzy modelling in engineering; Class notes, Civil Engineering Faculty, Istanbul Technical Univ., Istanbul, Turkey (in Turkish).

Sinha Jitendra R K, Sahu Agrawal Avinash, Pali A K and Sinha B L 2013 Rainfall runoff modelling using multi-layer perceptron technique - A case study of the Upper Kharun Catchments in Chhattishgarh; J. Agr. Eng. 50(2) 43-51.

Shivakumar B, Jayawardhane A W and Fernando T M K G 2002 River flow forecasting: Use of phase space reconstruction and artificial neural network approaches; $J$. Hydrol. 265 225-245.

Smith J and Sli R N 1995 Neural network model for rainfall runoff process; J. Water Res. Plan. Manag. ASCE 121 49-508.

Tayfur G and Singh V P 2006 ANN and fuzzy logic models for simulating event-based rainfall-runoff; J. Hydrol. Eng. 132 1321-1330.

Tayfur G, Moramorco T and Singh V P 2003 Predicting and forecasting flow discharge at sites receiving significant lateral inflow; Hydrol. Process. 21 1848-1859.

Tokar A S and Johnson P A 1999 Rainfall-runoff modelling using artificial neural networks; J. Hydrol. Eng. 4 232239 .

Tilmant A, Vanclooster M, Duckstein L and Persoons E 2002 Comparison of fuzzy and nonfuzzy optimal reservoir operating policies; J. Water Resour. Plan. Manag. 128(6) 390-398.

Yeshewatesfa Hundecha, Andrass Bardossey and Hanse Warner Theisen 2001 Development of fuzzy logic based rainfall runoff model; J. Hydrol. Sci. 46(3) $363-376$.

Zadeh L A 1965 Fuzzy sets; Information and Control 8(3) $338-353$. 